\title{
Review Paper on Properties of Concrete Partial Replacement of Fine Aggregate \& Cement
}

\author{
Khan Gayasuddin Abdul Rauf ${ }^{1}$, Pratiksha Malviya ${ }^{2}$ \\ ${ }^{1}$ M.Tech Scholar, ${ }^{2}$ Professor \\ Department of Civil Engineering, Millennium Institute of Technology, \\ Bhopal, Madhya Pradesh, India
}

\begin{abstract}
The main objective of this research is to investigate the use of fly ash and other is Stone dust as partial replacement of cement and concrete production. In this research we analyze the strength of concrete made with using these waste materials one is Fly ash and other is Stone dust. The Fly as his used as 20\% replace by weight of cement and Stone Dust as the partial replacement of Fine Aggregate from 0\%, 10\%, $20 \%, 30 \%$ and $40 \%$. The grade of the concrete here is M-30 grade.
\end{abstract}

Keywords: fly ash, Stone Dust, Mix Design, Compressive Strength Test, Flexure Test, Split Tensile Test

\section{INTRODUCTION}

Concrete is the most widely used construction material in the world it is a mixture of cement, sand, coarse aggregate and water. Cement is binding material in the cement concrete and its role is to provide strength to concrete. Cement fills up voids existing in the fine aggregate and makes the concrete impermeable. Provides strength to concrete on setting and hardening and binds the aggregate into a solid mass by virtue of its setting and hardening properties when mixed with water. Fine aggregate consist of small angular or rounded grains of silica. It is commonly used as the fine aggregate in cement concrete. It fills the voids existing in the coarse aggregate it reduces shrinkage cracking of concrete. It helps in hardening of cement by allowing the water through its voids. To form hard mass of silicates as it is believed that some chemical reaction take place between silica of sand and constituents of cement, Coarse aggregate makes solid and hard mass of concrete with cement and sand it increase the crushing strength of concrete.

\section{Strength of Concrete}

The strength of concrete is very much dependent upon the hydration reaction just discussed. Water plays a critical role, particularly the amount used. The strength of concrete increases when less water is used to make concrete, the hydration reaction itself consumes a specific amount of water. Concrete is actually mixed with more water than is needed for the hydration reactions. This extra water is added to give concrete sufficient workability. Flowing concrete is desired to achieve proper filling and the composition of the forms. The water not consumed in the hydration reaction will remain in the microstructure pore space. These pores make the concrete weaker due to the lack of strength-forming calcium silicate hydrate bonds. Some pairs will remain no matter how well the concrete has been compacted.

\section{RELATED WORK}

\section{P. P. Shanbhag, V. G. Patwari JULY 2017,}

The present study is aimed at utilizing Waste marble powder and quarry sand as partial replacement of cement and fine aggregate in concrete and comparing it with conventional concrete. This experimental investigation is carried out in three phases in 1st phase M20 grade of concrete is produced by replacing cement with $0 \%, 5 \%, 10 \%$ \& $15 \%$ of Marble Powder. In 2 nd phase concrete is produced by replacing sand with $0 \%, 30 \%, 40 \% \& 50 \%$ of quarry sand and in 3rd phase concrete is produced by replacing cement and fine aggregate in the percentage of $0 \%, 5 \%, 10 \%$ \& $15 \%$ of Marble Powder and $0 \%, 30 \%, 40 \%$ \& $50 \%$ of quarry dust respectively. It is found that the studies of 
concrete made of waste marble powder and quarry sand increases at $10 \%$ and $40 \%$ respectively. Therefore the quarry dust and waste marble powder should be used in construction works, then the cost of construction would be saved significantly and the natural resources would be used efficiently.

\section{Mohammadreza Mirzahosseini and Kyle A. Riding June 2015,}

Have examined that the finely ground glass hs the potential for pozzolanic reactivity and can fill in as a supplementary cementitious material uniform structure, amorphous nature, and high silica content influenced ground to glass perfect for concentrate the impacts of glass write and molecule estimate on smooth material reactivity at various temperature. This investigation centres around how the blend of glass composes and particles sizes influences the microstructure and execution properties of cementitious framework containing glass cullet as a supplementary cementitious materials. They found that the response rate pozzolanicity and hydration degree capability of four arrangements of consolidated glass composes and sizes were examined utilizing isothermal calorimetric concoction shrinkage, thermo gravimetric investigation and examination of checking electron magnifying lens pictures, additionally compressive quality and water sorptivity were performed on mortar tests to connect reactivity of cementitious materials containing glass to the execution of cementitious blends. Results demonstrated that joined glass can expands response rate and show pozzolanic properties, particularly when particles of clear and green glass underneath 25 micron were utilized at a curing temperature of 50 degree Celsius. The synchronous impact of sizes and kinds of glass cullet (surface zone) on response rate of Glass Powder additionally can be represented through a straight option mirroring that the surface territory would fundamentally influence glass cullet reactivity. However execution properties a cementitious framework containing joined glass writes and measure carried on diversely as they took after the weaker segment of the two particles.

\section{Brajesh Kumar Suman, Vikas Sribastava. April 2015.}

Have considered that the stone tidy is such an elective material which can be adequately being utilized as a part of development as halfway substitution of normal sand. In this examination, a test program was completed to think about the reasonableness and potential utilization of stone clean as incomplete substitution of fine total in concrete. To achieve this example were thrown for various substitution level at an interim of $\%$ to decide workability and compressive quality of cement at various level of fine total with stone tidy. Results demonstrate that ideal supplanting with stone tidy is $60 \%$ in light of compressive quality.

\section{Arame Niang, Nathalie Roy, and Arezki Tagnit- Homou March 2015,}

Have contemplated that Concrete created by utilizing Glass Powder as a fastener demonstrates low piousness to chloride particles. Furthermore, broad research venture on the utilization of Glass Powder as cementitious material is in progress at the college of Sherbrook, Quebec, Canada. The north-eastern Canadian region of Quebec has a strategy on squander administration to advance the recuperation and administration of materials from the city, modern, business and institutional divisions. In this way new options for utilizing reused glass are required. Glass Powder contains around $70 \%$ silicon dioxide. In this manner the supplanting of $20 \%$ of bond with the consolidation of Glass Powder into the detailing of cement gives monetary and natural advantages. Besides, it has been demonstrated that solid with $20 \%$ Glass Powder has a low penetrability to chloride particles, which makes it an appropriate answer for reinfor4ced solid components subject to eroding condition, for example, deicing items or a salty climate. The outcomes from an investigation on the auxiliary conduct of strengthened solid section consolidating Glass Powder. The solid section made with Glass Powder indicate attractive basic conduct. The outcomes demonstrated that for a water-folio proportion of 0.4 the substitution of $20 \%$ of bond by Glass Powder postponed breaking o the solid cover and marginally enhanced the heap conveying limit. For water-folio ration 0.55 the outcomes for segments with Glass Powder tried at 91 days were still somewhat lower than those without Glass Powder. In any case, the distinction was littler than for sections with a similar water-cover proportion that were tried at 28 days. Generally, the outcomes demonstrated that auxiliary conduct of fortified solid segments made utilizing concrete with Glass Powder is like section made with ordinary cement with $20 \%$ Glass Powder for the development of practical building structures.

Dr. Lalit Kumar, Er. Arvinder Singh. January 2015.

Have examine the likelihood of utilizing pounded stone tidy as fine total incompletely or completely 
with various evaluations of solid composites. The reasonableness of smashed stone tidy waste as a fine total for concrete has been surveyed by contrasting its fundamental properties and that of traditional cement. Two essential blends were decided for regular sand to accomplish M25 and M30 review concrete. The comparable blends were acquired by supplanting regular sand by stone tidy mostly and completely. The test outcome demonstrates the smashed stone tidy can be utilized viably to supplant characteristic sand in concrete. In the exploratory investigation of quality attributes of solid utilizing smashed stone tidy as fine total it is discovered that there is increment in compressive quality, flexure quality and elasticity.

\section{Sadoon Abdallah, Mizi Fan June 2014.}

Have examines that the attributes of cement containing fine pulverized glass amid its procedure, the best proportion of fine squashed glass which prompts higher quality of cement with a specific end goal to create solid squares, and the impacts of waste glass substitution on extension caused by Alkali-Silica response. The droop unit weight, compressive quality part rigidity, flexure quality modulus of flexibility, ultrasonic heartbeat speed, dry thickness, water retention and Alkali-Silica response were examined as far as waste glass content $(0 \%, 5 \%, 15 \%$ and $20 \%)$ under various curing age of 7, 14, and 28 days. It was discovered that the droop of cement containing waste glass as fine total supplanting diminished with expanded in the waste glass however without loss of workability. The compressive, part ductile and flexure quality of cement with $20 \%$ waste glass content expanded by $5.28 \%, 18.38 \%$ and $8.92 \%$ separately at 28 days. The coxes with squander glass substitution demonstrated a denser inside solid structure or more steady structure under ultrasonic heartbeat speed evaluation. There was a reasonable diminished in the water retention with an increment of waste glass total proportion, and an unmistakable decrease in the development of the waste glass solid, demonstrating a soluble base silica response in solid which happened between the dynamic silica of waste glass and silica of concrete glue.

\section{Ali A. Aliabdo, Abd Elmoaty M. Abd Elmoaty, Esraa M. Auda. January 2014,}

Have discover the utilization of marble clean in solid creation as bond substitution or as sand substitution (bond expansion) continuously improves both of the Mechanical and Physical properties of cement particularly with bring down w/c proportion. Marble clean demonstrated a filler impact in concrete and had no recognizable part in the hydration procedure. However concrete made with marble tidy as sand substitution accomplished better execution contrasted with concrete made with marble tidy as bond substitution.

\section{Vijayalakshmi, A. S. S. Sekar., G. Ganesh PrabhuSeptember 2013,}

Have examined that the rock stone handling industry produces huge amounts of non-biodegradable fine powder squanders and usage of that risky waste in solid generation will prompt green condition and reasonable solid innovation. Solid blend were set up by $0 \%, 5 \%, 10 \%, 15 \%, 20 \%$ and $25 \%$ of fine total substituted by stone powder squander. The acquired test outcomes were demonstrated that the substitution of regular sand by rock powder squander up to $15 \%$ of any definition is good for the solid making without antagonistically influencing the quality and strength criteria. Notwithstanding it is prescribed that the rock powder waste ought to be subjected to a compound blanching process preceding mix in the solid to build the sulfate protection.

Dr. G. Vijayakumar, Ms H. Vishliny, Dr. D. Govindarajulu Feb 2013

Have contemplated that finely powdered waste glasses are utilized as a fractional substitution of bond in concrete and contrasted it and regular cement. This work looks at that the likelihood of utilizing Glass Powder as a fractional substitution as $10 \%, 20 \%, 30 \%$ and $40 \%$. What's more, tried for its compressive, ductile and flexure quality up to 60 days of age and were contrasted and those of traditional solid: frame the outcomes acquired, it is discovered that Glass Powder can be utilized as bond substitution material upto molecule measure under 75 micron to avoid salt silica response.

Kalingarani et al. (2012)

concluded that Interlocking concrete paver block (ICPB) is having advantages in the exterior flooring. His aim of the study is making ICPB by using a maximum amount of industrial waste like fly ash and copper slag.

\section{Vaz Aaron et al. (2012)}

found that now a days cement concrete is second mostly used commodity material in the world, because cement is responsible for producing a large amount of carbon dioxide \& also responsible for 
global warming effect. Now a dyas Geopolymer concrete used as an option for OPC in precast concrete products. Geopolymer concrete is a eco friendly option for waste stabilization. Geopolymer concrete paver blocks have advantages on OPC in form of high compressive strength. They also have high early strength gain curing time 24 hours at $60^{\circ} \mathrm{C}$ and OPC is curing 28 days in water so geopolymer concrete used Benefit in the manufacture paver block.

\section{Problem Identification}

$>$ Natural resources are depending past researches for substitute construction materials is being done rapidly.

$>$ Some of factory serape, garbage's by products are useful as substitute for natural resources .Such materials cause additional problems of storage, environmental eco and transportation as well literature survey indicated those glass ,serape of a glass factory can be used as substitute material for fine aggregate.

$>$ Glass powder is generated in a large amount in the production of glass industries and crusher plants, window repair shops, old tube light, electric bulb etc.

\section{Objective}

$>$ To find out alternative materials as partial replacement of cement and fine aggregate (sand).

$>$ To check the workability of the concrete by adding fly ash and stone dust.

\section{CONCLUSION}

The compressive strength of the concrete by replacing the $40 \%$ sand by stone dust and $20 \%$ cement by the fly ash the strength increases.

\section{REFERENCES}

1. Ahmed Omran, Arezki Tagnit-Hamou. "Performance of glass-powder concrete in field applications", Construction and Building Material. Volume-109, 15 April 2016, Pages 84-95.

2. Ali A. Aliabdo, Abd Elmoaty M. Abd Elmoaty, Esraa M. Auda. "Re-use of waste marble dust in the production of cement and concrete", Construction and Building Materials, Volume 50, 15 January 2014,, Pages 28-41.
3. Arame Niang, Nathalie Roy, and Arezki TagnitHomou. "Structural Behaviour of Concrete Incorporating Glass Powder Used in Reinforced Concrete Columns", Journal of Structural Engineering. ASCE, March 2015, Vol-141, No. 3.

4. Brajesh Kumar Suman, Vikas Sribastava. "Utilization of stone dust as fine aggregate replacement in concrete", Journal of Multidisciplinary Engineering Science and Technology ISSN 3159-0040, Vol 2, Issue 4, April 2015.

5. Dr. Lalit Kumar, Er. Arvinder Singh. "A Study on the strength of concrete using crushed stone dust as fine aggregate", International Journal for Research Applied Science \& Engineering Technology. ISSN: 2321-9653, Volume 3 Issue I, January 2015.

6. Hocine Siad, Mohamad Lachemi, Mustafa, Sahmaran, Khandaker M. Anwar Hossain, "Effect of glass powder on sulfuric acid resistance of cementitious materials", Construction and Building Materials, Volume 113, 15 June 2016, Pages 163-173.

7. IS: 1489-1991. Portland Pozzolana cement Specification Part 1: Fly Ash Based, Bureau of Indian Standard Institution, New Delhi.

8. IS: 383-1970. Specification for coarse and Fine Aggregates from natural sources for concrete.

9. IS: 5816-1999. Method of Test Splitting Tensile Strength of Concrete. Bureau of Indian standards. New Delhi, India.

10. K.T. Krishnaswamy, A. Kamsundara Rao, A. A. Khandekar. "Concrete Technology", Dhanpat Rai Publications.

11. Kaveh Afshinnia, Prasada Rao Rangaraju. "Impact of combined use of ground fly ashand crushed glass aggregate on selected properties of Portland cement concrete", Construction and Building Materials, volume 117, 1 August 2016.

12. M. Vijayalakshmi, A.S.S. Sekar., G. Ganesh Prabhu. "Strength and durability properties of concrete made with granite dindustry waste", Construction and Building Materials, Volume 46, September 2013, Page 1-7. 